\title{
Association between siesta (daytime sleep), dietary patterns and the presence of metabolic syndrome in elderly living in Mediterranean area (MEDIS study): The moderating effect of gender
}

Georgousopoulou, EN, Naumovski, N, Mellor, DD, Tyrovolas, S, Piscopo, S, Valacchi, G, Tsakountakis, N, Zeimbekis, A, Bountziouka, V, Gotsis, E, Metallinos, G, Tyrovola, D, Kellett, J, Foscolou, A, Tur, JA, Matalas, AL, Lionis, C, Polychronopoulos, E, Sidossis, L \& Panagiotakos, DB

Author post-print (accepted) deposited by Coventry University's Repository

Original citation \& hyperlink:

Georgousopoulou, EN, Naumovski, N, Mellor, DD, Tyrovolas, S, Piscopo, S, Valacchi, G, Tsakountakis, N, Zeimbekis, A, Bountziouka, V, Gotsis, E, Metallinos, G, Tyrovola, D, Kellett, J, Foscolou, A, Tur, JA, Matalas, AL, Lionis, C, Polychronopoulos, E, Sidossis, L \& Panagiotakos, DB 2016, 'Association between siesta (daytime sleep), dietary patterns and the presence of metabolic syndrome in elderly living in Mediterranean area (MEDIS study): The moderating effect of gender' Journal of Nutrition, Health and Aging, vol (in press), pp. (in press)

https://dx.doi.org/10.1007/s12603-016-0865-0

DOI $\quad 10.1007 / \mathrm{s} 12603-016-0865-0$

ISSN 1279-7707

ESSN $\quad 1760-4788$

Publisher: Springer

The final publication is available at Springer via http://dx.doi.org/10.1007/s12603-016-0865-0

Copyright $(\subset$ and Moral Rights are retained by the author(s) and/ or other copyright owners. A copy can be downloaded for personal non-commercial research or study, without prior permission or charge. This item cannot be reproduced or quoted extensively from without first obtaining permission in writing from the copyright holder(s). The content must not be changed in any way or sold commercially in any format or medium without the formal permission of the copyright holders.

This document is the author's post-print version, incorporating any revisions agreed during the peerreview process. Some differences between the published version and this version may remain and you are advised to consult the published version if you wish to cite from it. 
1 ASSOCIATION BETWEEN SIESTA (DAYTIME SLEEP), DIETARY PATTERNS

AND THE PRESENCE OF METABOLIC SYNDROME IN ELDERLY LIVING IN

Ekavi N. Georgousopoulou ${ }^{1,2}$, Nenad Naumovski ${ }^{2}$, Duane

D. Mellor ${ }^{2}$, Stefanos

Tyrovolas ${ }^{1,3}$, Suzanne

Piscopo ${ }^{4}$, Giuseppe $\quad$ Valacchi $^{5}$, Nikos Tsakountakis ${ }^{6}$, Akis

8 Panagiotakos $^{1}$ and the MEDIS study group

${ }^{1}$ Department of Nutrition and Dietetics, School of Health Science and Education, Harokopio University, Athens, Greece; ${ }^{2}$ Faculty of Health, University of Canberra, Canberra, Australia; ${ }^{3}$ Parc Sanitari Sant Joan de Déu, Fundació Sant Joan de Déu, CIBERSAM, Universitat de Barcelona, Barcelona, Spain; ${ }^{4}$ University of Malta, Nutrition, Family and Consumer Studies Office, Msida, Republic of Malta; ${ }^{5}$ Department of Life Sciences and Biotechnology, University of Ferrara, Ferrara, Italy; ${ }^{6}$ Clinic of Social and Family Medicine, School of Medicine, University of Crete, Heraklion, Greece; ${ }^{7}$ Health Center of Kalloni, General Hospital of Mitilini, Mitilini, Greece; ${ }^{8}$ Research Group on Community Nutrition and Oxidative Stress, Universitat de les Illes Balears \& CIBERobn, E-07122 Palma de Mallorca, Spain; ${ }^{9}$ Department of Kinesiology and Health, Rutgers Univeristy, New Jersey, USA.

\section{Corresponding author:}

Prof Demosthenes B Panagiotakos

46 Paleon Polemiston St. Glyfada, Attica, 166 74, Greece

Tel. +30 210-9549332 - +30 210-9600719 (Fax) 
ABSTRACT

Objectives: Several lifestyle parameters including diet, physical activity and sleep were associated in isolation with the presence of Metabolic Syndrome (MetS) in adults, to date there is a paucity of studies which evaluated their combined role aging populations and especially with respect to gender. Therefore, the aim of the present study was to provide a global consideration of the lifestyle factors associated with MetS among elderly individuals.

Design: Cross-sectional observational study. Setting: 21 Mediterranean islands and the rural Mani region (Peloponnesus) of Greece. Participants: during 2005-2015, 2749 older (aged 65-100 years) from were voluntarily enrolled in the study. Measurements: Dietary habits, energy intake, physical activity status, socio-demographic characteristics, lifestyle parameters (sleeping and smoking habits) and clinical profile aspects were derived through standard procedures. The presence of MetS was defined using the definition provided by NCEP ATP III (revised) and cluster analysis was used to identify overall dietary habit patterns. Results: The overall prevalence of MetS in the study sample was $36.2 \%$, but occurred more frequently in females (40.0\% vs. $31.8 \%$, respectively, $\mathrm{p}=0.03$ ). Individuals with MetS were more likely to sleep during the day ( $89.4 \%$ vs. $76.8 \%$ respectively, $\mathrm{p}=0.039)$ and frequent 'siesta' was positively linked to the odds of MetS presence in females (Odds Ratio (OR) $=3.43,95 \%$ Confidence Intervals (CI): 1.08-10.9), but not for men $(\mathrm{p}=0.999)$. The lower carbohydrate (i.e., $45.2 \%$ of total daily energy, $120 \pm 16 \mathrm{gr} /$ day) dietary cluster was inversely associated with the odds for MetS presence, but only for men ( $\mathrm{OR}=0.094$, 95\%CI: 0.010-0.883).

Conclusions: Lifestyle parameters including sleep and diet quality are strongly associated with the presence of MetS in elderly cohort, but different their level of influence appears to be different, depending on gender. Further research is needed to better consider the role of lifestyle characteristics in the management of MetS in clinical practice. 
54 Key words: Metabolic Syndrome; Sleep; Elderly; Diet; Lifestyle; MEDIS; siesta;

55 Mediterranean-type diet

56 


\section{Introduction}

Metabolic syndrome (MetS) is a complex disorder, defined as a cluster of interacting metabolic abnormalities which includes; insulin resistance, central obesity, dyslipidemia, impaired endothelial function, increased arterial blood pressure levels, hypercoagulation and low-grade inflammation $(1,2)$. MetS diagnosis is associated with an increased risk of developing type 2 diabetes mellitus, atherogenesis and cardiovascular disease (CVD), thus, its management is in the pivotal point for CVD primary prevention (3). However, MetS is an increasingly prevalent condition, present in approximately $20-30 \%$ of the adult population worldwide (4), with prevalence increasing with age, reaching almost $60 \%$ in older cohorts (5). Additionally, this apparent exponential increase in incidence appears to parallel that seen in obesity which has become a modern epidemic challenging public health systems. This has led to numerous studies investigating the pathophysiology underpinning MetS in order to decrease in its rate of incidence (6-9)

A number of lifestyle parameters have been linked to the risk of developing MetS including sedentary lifestyle (10), unhealthy dietary habits (11) and more recently, suboptimal quantities of sleep $(12,13)$ have been associated with higher risk of developing MetS within other health outcomes. More specifically, with respect to physical activity levels, subjects who engage in vigorous physical activity decreased their odds of developing MetS by up to $40 \%$ (10), whilst adherence to a Mediterranean-type diet offers further protection against the development of MetS (14). Moreover, recent research suggests that adherence to Mediterranean diet is linked to better physical performance among elderly (15), suggesting the potential of a synergistic effect against MetS. With respect to sleeping habits and behavior, not only the quantity of sleeping hours appears to be predictive (12), but also the engaging in daytime sleep habits, typically known as "siesta" that lasts more than one hour has been proposed as an aggravating factor that is associated with increased odds of 
82 MetS presence in middle-aged individuals. The latter finding was shown to be a significant relationship only for females, suggesting a differentiation between the two genders in the risk factors for the development of MetS (16). This has led to increased interest and more focused investigations of how MetS appears to manifest differently in males and females, highlighting the emerging need to consider different therapeutic and therefore preventative approaches for the two genders (17).

To date, despite the research that has evaluated the effects of the aforementioned lifestyle parameters on the presence and development of MetS, no attempt has been made to incorporate these parameters into the same analysis in order to explore potential interactions or synergistic effects between these factors. Therefore, the aim of the present study was to investigate potential interactions between lifestyle factors that may link the presence of MetS with dietary patterns, sleeping habits, physical activity status and other health characteristics of an elderly cohort.

\section{Materials and methods}

\section{Methodology}

The Mediterranean Islands (MEDIS) study is an ongoing, large-scale, multinational project in the Mediterranean region, which is exploring the association between lifestyle habits, psychosocial characteristics and living environment, on cardiometabolic factors, among older people (>65 years), residing in the Mediterranean area.

\section{The Study's sample}

Between 2005-2015, a random population-based, multistage sampling method (i.e., age group, 3 levels (65 - 75, 75 - 85, $85 \pm$ ) and 2 sex levels) was used to voluntarily enrol older men and women people from 22 Mediterranean islands: including Malta Republic ( $\mathrm{n}=250)$, 
Sardinia $(n=60)$ and Sicily $(n=50)$ in Italy, Mallorca and Menorca $(n=111)$, Republic of

107 Cyprus ( $n=300)$, Gökçeada $(n=55)$ in Turkey, and the Greek islands of Lesvos $(n=142)$,

Samothraki ( $\mathrm{n}=100)$, Cephalonia $(\mathrm{n}=115)$, Crete $(\mathrm{n}=131)$, Corfu $(\mathrm{n}=149)$, Limnos $(\mathrm{n}=150)$,

Ikaria ( $n=76)$, Syros ( $n=151)$, Naxos $(n=145)$, Zakynthos $(n=103)$, Salamina $(n=147)$, Kassos $(n=52)$, Rhodes and Karpathos $(n=149)$, Tinos $(n=129)$, as well as the rural region of east Mani ( $\mathrm{n}=295,157$ men aged $75 \pm 7$ years and 138 women aged $74 \pm 7$ years) (a Greek peninsula, which is in the southeast, continental area of Europe, with a total population of 13,005 people (census 2011), which has morphological and cultural specificities, which are not common across in the rest of Greece. The participation rate varied according to region, from $75 \%$ to $89 \%$. Thus, for the present work information from 1,369 men, aged $75 \pm 8$ years and 1,380 women, aged $74 \pm 7$ years were analysed.

Individuals who resided in assisted-living centres, had a clinical history of cardiovascular disease (CVD) or cancer, or had left the island for a considerable period of time during their life (i.e., >5 years) were excluded from participating in the study; these criteria were applied because the study aimed to assess lifestyle patterns that were not a response of individuals modifying how they live due to existing chronic health care conditions or by environmental factors, other than their living milieu. A multidisciplinary questionnaire and standard procedures.

\section{Bioethics}

The study followed the ethical considerations provided by the World Medical Association (52 ${ }^{\text {nd }}$ WMA General Assembly, Edinburgh, Scotland; October 2000). The Institutional Ethics 
informed about the aims and procedures of the study and gave their consent prior to being interviewed.

\section{Evaluation of clinical characteristics}

133 All of the measurements taken in the different study centres were standardized and the (www.who.int/substance_abuse/research_tools/translation/en/).

Height and weight were measured using standard procedures to attain body mass index $(\mathrm{BMI})$ scores $\left(\mathrm{kg} / \mathrm{m}^{2}\right)$. Waist circumference $(\mathrm{cm})$ was measured at the midpoint between the $12^{\text {th }}$ rib and the iliac crest and hip circumference $(\mathrm{cm})$ was measured around the widest part of the buttocks. Central adiposity was defined as waist circumference greater than $102 \mathrm{~cm}$ for men and $88 \mathrm{~cm}$ for women. Diabetes mellitus (type 2) was determined by fasting plasma glucose tests and was analysed in accordance with the American Diabetes Association diagnostic criteria (glycated haemoglobin A1C $>6.5 \%$ or fasting blood glucose levels greater than $126 \mathrm{mg} / \mathrm{dl}$ or 2 -h plasma glucose $>200 \mathrm{mg} / \mathrm{dl}$ during an oral glucose tolerance testOGTT- or a random plasma glucose $>200 \mathrm{mg} / \mathrm{dl}$ or they have been already diagnosed with diabetes). Participants who had blood pressure levels above 140/90 $\mathrm{mmHg}$ or used antihypertensive medications were classified as hypertensive. Fasting blood lipids levels (HDL-, LDL-cholesterol and triglycerides) were also recorded and hypercholesterolemia was defined as total serum cholesterol levels greater than $200 \mathrm{mg} / \mathrm{dL}$ or the use of lipid-lowering agents according to the NCEP ATP III guidelines (18). The coefficient of variation for the blood measurements was less than 5\%. The presence of MetS was defined using the definition provided by NCEP ATP III (revised); three or more of the following metabolic components present: waist circumference $\geq 102 \mathrm{~cm}$ for males or $\geq 88 \mathrm{~cm}$ for females; 
triglycerides level $\geq 150 \mathrm{mg} / \mathrm{dl}$; HDL cholesterol level $<40 \mathrm{mg} / \mathrm{dL}$ for males or $<50 \mathrm{mg} / \mathrm{dL}$ for females; blood pressure $\geq 130 / 85 \mathrm{mmHg}$; fasting blood glucose $\geq 100 \mathrm{mg} / \mathrm{dL}(19)$.

156

157

\section{Evaluation of lifestyle and socio-demographic characteristics}

Dietary habits were assessed through a semi-quantitative, validated and reproducible foodfrequency questionnaire (20). Trained dietitians estimated the mean daily energy intake and the mean percentage of total energy derived from dietary carbohydrates. To evaluate the level of adherence to the Mediterranean diet, the MedDietScore (possible range 0-55) was used (21). Higher values for this diet score being indicative of greater adherence to the Mediterranean diet. Participants were also encouraged to report the duration of following their dietary pattern (i.e., number of years this pattern had been in place). Basic sociodemographic characteristics such as age, sex, occupational status, household composition, education level (described as number of school years), residing in rural or urban area, as well as lifestyle characteristics, such as smoking habits and physical activity status, data on frequency of sleeping during the day (siesta) defined as having a siesta for more than five days per week (22), were also recorded. Current smokers were defined as smokers at the time of the interview, whereas former smokers were defined as those who previously smoked, but had not done so for a year or more. Current and former smokers were defined as had 'ever smokers'. The remaining participants were defined as occasional or non-smokers. Physical activity was evaluated in MET-minutes per week, using the shortened, translated and validated into Greek, version of the self-reported International Physical Activity Questionnaire (IPAQ) (23). Frequency (times per week), duration (minutes per session) and intensity of physical activity during sports, occupation and/or leisure activities were assessed. Participants were instructed to report only episodes of activity lasting at least $10 \mathrm{~min}$, since this is the minimum required to achieve health benefits. Physically active individuals were 
defined those who reported at least 3 MET-min. Daily walking time was calculated by using the IPAQ question about walking (times per week and average time spent).

Further in depth details about the MEDIS study protocols have been extensively been published elsewhere $(24,25)$.

\section{Statistical analysis}

Continuous variables are expressed as mean \pm standard deviation for variables following assessing for normal distribution, or median (inter-quartile range) for variables not following normal distribution. Normality was tested using P-P plots. Differences in continuous variables between MetS and non-MetS subjects were evaluated with the Student's t-test for normally distributed parameters and the Mann-Whitney test for non-parametric variables. Nominal variables are presented as frequencies and relative frequencies (\%). Pearson's Chisquare test was used to assess the association between two nominal variables. In order to group subjects based on dietary characteristics (MedDietScore, total daily energy intake, percentage of total energy provided by carbohydrates intake), clustered analysis was also performed, particularly the k-means technique. As a measure of distance, the Euclidian distance was used for continuous variables. For the selection of the final number of clusters, the aforementioned methods were used repeatedly, by changing the predetermined number of clusters each time, and the results were analyzed empirically. The decision on the final number of clusters used in our analysis depended on the nature of the data.

Binary logistic regression models were used to evaluate the association between participants' characteristics (i.e., age, sex, BMI, physical activity, cluster of dietary habits, smoking habits, siesta habit) and presence of MetS. Results are expressed as odds ratios and the $95 \%$ confidence intervals. Stratified analysis by gender was performed due to suspected interaction between gender and the role of siesta, which was tested after relevant findings in 
literature. In order to estimate the additive value of each variable entered in the logistic models, a likelihood ratio test for nested models was performed for each variable (26), separately in men and women. The level of statistical significance for interaction terms was set at alpha $=0.05$ and all statistical tests were performed for 2-tailed hypotheses. Type I error was predefined at 0.05 . Statistical analysis was performed in IBM SPSS version 23.0 (Armonk, NY: IBM Corp.).

\section{Results}

The overall prevalence of MetS in the study sample was $36.2 \%$, with females being more likely to meet the diagnostic criteria than males (40.0\% vs. $31.8 \%$, respectively, $\mathrm{p}=0.03$ ). Regarding its association with age, MetS was more common among individuals aged between 65 and 80 years old than the very old (i.e., over 80 years old) (38.3\% vs. $29.5 \%$ respectively, $\mathrm{p}=0.008)$. Moreover, subjects who adhered to a Mediterranean diet pattern in the highest tertile were less likely to have MetS as compared subjects with low or moderate adherence to this dietary pattern $(29.7 \%$ vs. $37.3 \%$ respectively, $\mathrm{p}=0.05)$. Descriptive characteristics of the study sample, divided in two groups in respect to MetS presence, are summarized in Table 1.

Individuals with MetS, when compared to healthy individuals, were more likely to be females $(59.2 \%$ vs. $51.3 \%$ respectively, $\mathrm{p}=0.003)$, currently employed in the workforce ( $38.1 \%$ vs. $29.1 \%$, respectively, $\mathrm{p}=0.050)$ and with lower educational level as compared to MerS free individuals $(2.2 \%$ studied for more than 12 school years vs. 6.3\%, respectively, $\mathrm{p}=0.003$ ). Individuals with MetS had significantly higher BMI than healthy subjects $(29.7 \%$ vs. $39.9 \%$ respectively, $\mathrm{p}=0.001)$ were less likely to be smokers $(10.1 \%$ vs. $16.0 \%$ respectively, $\mathrm{p}=0.005)$ and had dramatically increased prevalence of diabetes $(60.3 \%$ vs. 
$0.3 \%, \mathrm{p}<0.001)$, hypertension $(88.7 \%$ vs. $61.2 \%, \mathrm{p}<0.001)$ and hypercholesterolemia $(77.3 \%$ vs. $41.6 \%, \mathrm{p}<0.001)$. Moreover, individuals with MetS were more likely to sleep during the day more often than subjects without MetS (89.4\% vs. $76.8 \%$ respectively, $\mathrm{p}=0.039)$ and less likely to reside in a rural area $(62.9 \%$ vs. $70.8 \%$ respectively, $\mathrm{p}<0.001)$.

\section{[Table 1]}

With respect to dietary patterns, the variables chosen were highly correlated to the physiology of MetS, i.e. daily energy intake, daily amount of carbohydrates and MedDietScore were used as the initial variables to investigate the presence of specific clusters. The 2-means cluster analysis lead to the classification of the individuals into two clusters according to the aforementioned variables ( $\mathrm{p}$-values for between clusters variables $<0.05)$. The first cluster represented $37.0 \%$ of the participants and was characterized by higher energy intake, high daily percentage of carbohydrates energy and higher MedDietScore named "Healthy High Carbs diet", whilst the second cluster represented $63.0 \%$ of the participants and was characterized by lower energy intake, a reduction in the amount of total energy obtained from carbohydrates (45.2\%, depicting $120 \pm 16 \mathrm{gr} /$ day) and lower MedDietScore named "Reduced Carbs diet". No significant differences were observed between the gender and the cluster membership $(\mathrm{p}=0.761)$.

When multivariable binary logistic model was implemented with the presence of MetS as the dependent variable, siesta habit was an independent positive predictor of the presence of MetS (Odds Ratio $(\mathrm{OR})=4.049$, 95\% Confidence Interval (CI): 1.310-12.518) after adjusting for age, gender, smoking status, daily walking time, BMI and dietary cluster membership (Table 2, Model 1). Among these parameters, only BMI was an independent predictor of MetS presence (OR per one unit increase=1.166, 95\%CI: 1.069-1.272), independently of the same characteristics (Table 2, Model 1). Due to suspected interaction 
between siesta and gender regarding their role in insulin resistance, the interaction term was significant $(\mathrm{p}=0.05)$, so the analysis was further stratified by gender (Table 2, Models 2, 3).

As predicted, gender had a moderating effect on the role of siesta in MetS presence, but also, the role of dietary cluster differentiated between genders. Specifically, frequent siesta was positively linked to 4 -fold higher odds of MetS presence in females (OR=3.43, 95\% CI: 1.08-10.9), but not for men ( $\mathrm{p}=0.999)$. Higher BMI was positively associated with higher odds of MetS presence for both genders (OR=1.87, 95\%CI: 1.17-3.00 for males and $\mathrm{OR}=1.13$, 95\%CI: $1.03-1.24$ for females). Finally, the dietary cluster characterized by reduced carbohydrates as compared to the healthy higher carbohydrates diet was inversely associated with the likelihood of MetS presence, only for men (OR=0.094, 95\%CI: 0.0100.883 ) but not for women (OR=1.10, 95\%CI: 0.424-2.83). Concerning the additive value of the variables in the logistic regression, the addition of BMI was important for both genders, whilst the pattern was totally different for the remaining variables. Only the siesta habit was found to have an important value over BMI ( $\mathrm{p}<0.001)$, whilst for men, almost every variable apart from siesta had an incremental ability (all p-values <0.05). As regards reduced carbohydrates diet, it was proven to have explanatory ability for MetS, even after being added on top of BMI, smoking, daily walking which were also important variables. However, the addition of siesta did not add any explanatory ability to the final model.

[Table 2]

\section{Discussion}

In the present study, the frequent daytime nap called siesta was associated with higher odds of MetS presence only in females, whilst this association was not significant for males. However, a low-carbohydrates dietary cluster was associated with lower odds of MetS presence only among males, but not for females. Moreover, this study confirmed that 
increased BMI is associated with higher odds of MetS presence in elderly, as well. These findings suggest that the daytime sleeping habit should be treated as a potential indicator of MetS presence among women and the reduced-carbohydrate dietary pattern should be treated as potential indicator of MetS absence among males. Furthermore, this was the first study (to our knowledge) to combine all these lifestyle parameters and the findings suggest the existence of a differentiated MetS expression by gender, warrants further examination.

The important finding concerning the sleeping habits was that siesta was positively associated with higher odds of MetS presence, but only for women, which is in accordance with a previous study finding where the authors reported that the prevalence of MetS was $44.5 \%$ among females who had a 0 to 1 napping day siesta, which was significantly higher than the prevalence of MetS among females with no daytime siesta $(35.0 \%, \mathrm{p}<0.001)$. In a multi-adjusted analysis, having a siesta for more than one hour was independently associated with an increased prevalence of MetS by $39 \%$ as compared to females not having day siesta. The authors also revealed that habitual napping was linked to higher prevalence of central obesity and hypertriglyceridemia and suggested these factors as potential explanations to the pathogenesis or simply be the defining characteristic of MetS associated with siesta. Furthermore, a recent meta-analysis revealed an important J-shape correlation with CVD and the length of siesta (27), but the role of gender was not investigated. In accordance to the present findings, no statistically significant associations were detected between daytime napping and metabolic syndrome among the male subjects (16).

A different trend by gender was also described in the present work for the role of dietary patterns on MetS prevalence. The latter confirmed previous findings, but being associated with different dietary patterns. Specifically, for men, adoption of an "animal and fried food" dietary pattern was positively related to MetS presence, whilst for women, the "high-salt and energy" dietary pattern was positively related to MetS presence (28). These 
differences could be related to the different hormonal profile that interacts with glucoserelated metabolic parameters. For instance, free testosterone levels and Sex Hormone Binding Globulin levels in women are strongly correlated with MetS presence, a finding that was weakened when it came to analysis in males, with low androgen levels potentially increasing MetS risk (29). Thyroid function, which regulates the most important endocrine pathways, not only is different between males and females, but also recent studies suggests that it affects the risk of developing MetS differently for the two genders (30). The gender differences in insulin resistance regulation could in part be explained by the findings of the present work, where the reduced carbohydrate diet was favourable for men, but was associated with no beneficial effects in women. It should be reminded that gender differences are prone to selection bias as elderly males and females in rural areas of Greece might not have the same access to recruitment for research purposes. However, the participation rates were adequately high to support the presented findings.

As highlighted above, the potential role of modifying lifestyle parameters is of utmost importance when it comes to reduce the burden of MetS, despite the fact that the trends are different influences between males and females. The present study provides new information on the factors associated with MetS in an elderly cohort, as well as on the combined role of lifestyle parameters and their interaction with sex. Moreover, this new information could provide additional information regarding the influences of aspects of the lifestyle treatment approach, by adding the potential for the role of sleeping patterns in the puzzle. Taking into account that dietary and physical activity interventions have already been shown to be successful in treating MetS (31), the addition of sleep interventions could help clinicians to increase the effectiveness of their interventions especially for female subjects and thus, reduce the burden of CVD, which is partially depending on the MetS presence (32). 
It is important to note that this is a cross-sectional survey and therefore lacks the ability to infer causal relationships. The measurements have been performed once and may be prone to measurement and reporting errors, however this methodology is commonly used worldwide, and this study used validated instruments and suitably qualified and trained staff, making the results comparable to other studies. The sleeping habits have been assessed only in terms of quantity and not quality, which could be equally important, this was employed as the measuring method is easier to implement and could be implemented in routine clinical practice.

\section{Conclusions}

Sleeping habits and dietary patterns are strongly associated with the presence of MetS in elderly women, but this association is not seen in elderly men. MetS in women is more linked to sleep than diet, whilst the opposite pattern is prevalent in men. Lifestyle assessment, including quantifying sleep in subjects with existing MetS should become an integral part of clinical practice, especially taking into account that MetS is a CVD risk factor of great significance, but fortunately is modifiable and therefore one that could easily be managed.

\section{AKNOWLEDGMENTS}

We are, particularly, grateful to the men and women from the islands of Malta, Sardinia, Sicily, Mallorca, Menorca, Cyprus, Lesvos, Samothraki, Crete, Corfu, Lemnos, Zakynthos, Cephalonia, Naxos, Syros, Ikaria, Salamina, Kassos, Rhodes, Karpathos, Tinos and the rural area of Mani, who participated in this research. The MEDIS study group is: M. Tornaritis, A. Polystipioti, M. Economou, (field investigators from Cyprus), A. Zeimbekis, K. Gelastopoulou, I. Vlachou (field investigator from Lesvos), I. Tsiligianni, M. Antonopoulou, N. Tsakountakis, K. Makri (field investigators from Crete), E. Niforatou, V. Alpentzou, M. Voutsadaki, M. Galiatsatos (field investigators from Cephalonia), K. Voutsa, E. Lioliou, M. 
351 Miheli (field investigator from Corfu), S. Tyrovolas, G. Pounis, A. Katsarou, E. 352 Papavenetiou, E. Apostolidou, G. Papavassiliou, P. Stravopodis (field investigators from 353 Zakynthos), E. Tourloukis, V. Bountziouka, A. Aggelopoulou, K. Kaldaridou, E. Qira, (field 354 investigators from Syros and Naxos), D. Tyrovolas (field investigator from Kassos), I. 355 Protopappa (field investigator from Ikaria), C. Prekas, O. Blaserou, K.D. Balafouti (field 356 investigators from Salamina), S. Ioakeimidi (field investigators from Rhodes and Karpathos), 357 A. Foscolou (field investigator from Tinos), T. Pakka (field investigator from Goekceada), A. 358 Mariolis, E. Petropoulou, A. Kalogerakou, K. Kalogerakou (field investigators from Mani), 359 S. Piscopo (field investigators from Malta), J.A. Tur (field investigators from Mallorca and 360 Menorca), G. Valacchi, B. Nanou (field investigators from Sardinia and Sicily) for their substantial assistance in the enrolment of the participants.

Conflict of interest: None to declare

Funding: The study has been funded by the Hellenic Heart Foundation, the Graduate program of the Department of Nutrition and Dietetics, Harokopio University in Athens, Greece and the Rutgers, The State University of New Jersey, USA. Stefano Tyrovolas' work was funded through a scholarship from the Foundation for Education and European Culture (IPEP). Josep A. Tur was funded by grants PI11/01791, CIBERobn CB12/03/30038, and 


\section{Table 1. Lifestyle, psychosocial and clinical characteristics of the MEDIS study participants $(n=2749)$ according to the presence of Metabolic Syndrome (MetS).}

\begin{tabular}{|c|c|c|c|c|c|c|}
\hline \multirow[b]{2}{*}{ Characteristics } & \multicolumn{3}{|c|}{ No MetS $(n=1754)$} & \multicolumn{3}{|c|}{ MetS $(n=995)$} \\
\hline & All & Males & Females & All & Males & Females \\
\hline Gender, men (\%) & $49.7 *$ & - & - & 40.8 & - & - \\
\hline Age (years) & $74 \pm 7.5$ & $75 \pm 7.7$ & $74 \pm 7.2$ & $74 \pm 6.3$ & $75 \pm 6.6$ & $73 \pm 6.0$ \\
\hline Retired, yes (\%) & $70.8 *$ & $76.1 \dagger$ & 65.4 & 62.9 & 67.0 & 60.0 \\
\hline Education: more than 12 years, & $6.3^{*}$ & 7.4 & $5.1 \uparrow$ & 2.2 & 4.2 & 0.8 \\
\hline \multicolumn{7}{|l|}{ yes $(\%)$} \\
\hline Living in rural area, yes $(\%)$ & $44.3^{*}$ & $44.0 \dagger$ & $44.5 \dagger$ & 29.0 & 30.1 & 28.2 \\
\hline Living alone, yes (\%) & 28.5 & 16.6 & 41.9 & 26.5 & 11.1 & 38.0 \\
\hline Smoking (current), yes (\%) & $16.0^{*}$ & $28.2 \dagger$ & 3.9 & 10.1 & 19.7 & 3.5 \\
\hline Body Mass Index $\left(\mathrm{kg} / \mathrm{m}^{2}\right)$ & $27.2 \pm 4.1 *$ & $26.9 \pm 3.7 \dagger$ & $27.6 \pm 4.5 \dagger$ & $31.2 \pm 4.9$ & $30 \pm 4.2$ & $32.0 \pm 5.2$ \\
\hline Hypercholesterolemia, yes (\%) & $41.6^{*}$ & $34.1 \dagger$ & $48.5 \dagger$ & 77.3 & 69.4 & 81.5 \\
\hline Hypertension, yes (\%) & $61.2 *$ & $54.1 \dagger$ & $59.3 \dagger$ & 88.7 & 80.5 & 93.1 \\
\hline Diabetes Mellitus, yes (\%) & $0.3^{*}$ & $0.4 \uparrow$ & $0.2 \dagger$ & 60.3 & 65.2 & 56.9 \\
\hline MedDietScore (range 0-55) & $33.6 \pm 4.1$ & $33 \pm 4.4$ & $34 \pm 3.9$ & $33.4 \pm 4.0$ & $33 \pm 4.2$ & $34 \pm 3.8$ \\
\hline Physical activity, yes (\%) & $39.9 *$ & 46.3 & $32.1 \dagger$ & 29.7 & 38.2 & 23.3 \\
\hline Daily Walking time (minutes)** & $60(20,120)$ & $45(20,120)$ & $60(20,120)$ & $45(15,120)$ & $60(15,98)$ & $40(15,120)$ \\
\hline Siesta (afternoon sleep), yes (\%) & $76.8^{*}$ & $83.3 \dagger$ & $71.9 \dagger$ & 89.4 & 93.3 & 88.2 \\
\hline Reduced Carbs diet, yes (\%) & 55.7 & 54.7 & 56.6 & 50.8 & 48.0 & 52.8 \\
\hline
\end{tabular}

$372 * *$ values are presented as median $\left(25^{\text {th }}, 75^{\text {th }}\right.$ percentiles $) . p$-values derived from Student's t-

373 test or non-parametric Mann-Whitney test for non-continuous variables and chi squared test

374 for nominal variables. * $\mathrm{p}$ for total sample $<0.05$, $\uparrow \mathrm{p}$ for within gender $<0.05$

375 
Table 2. Multivariable binary logistic regression model for the presence of MetS $(n=2749)$.

\begin{tabular}{|c|c|c|c|c|c|c|}
\hline \multirow[b]{2}{*}{ Variable } & \multicolumn{2}{|c|}{$\begin{array}{c}\text { All } \\
(n=2749)\end{array}$} & \multicolumn{2}{|c|}{$\begin{array}{c}\text { Males } \\
(n=1369)\end{array}$} & \multicolumn{2}{|c|}{$\begin{array}{l}\text { Females } \\
(n=1380)\end{array}$} \\
\hline & OR & $95 \% \mathrm{CI}$ & OR & $95 \% \mathrm{CI}$ & OR & $95 \% \mathrm{CI}$ \\
\hline Male vs. female & 0.59 & $0.23-1.49$ & - & - & - & - \\
\hline Model 1: Age (per 1 year) & 1.01 & $0.93-1.09$ & 0.89 & $0.74-3.00$ & 1.05 & $0.94-1.16$ \\
\hline Model 2: Model 1+Smoking (yes vs no) & 0.64 & $0.17-2.35$ & 0.69 & $1.01-1.73^{*}$ & 1.03 & $0.05-18.3$ \\
\hline Model 3: Model 2+BMI (per kg/m²) & 1.17 & $1.07-1.27$ & 1.87 & $1.17-3.00 *$ & 1.13 & $1.03-1.24^{*}$ \\
\hline \multicolumn{7}{|l|}{ Model 4a: Model 3+Daily walking (per } \\
\hline $\min /$ day) & 1.00 & $0.99-1.00$ & 0.99 & $0.98-1.00 *$ & 1.00 & $0.99-1.01$ \\
\hline \multicolumn{7}{|l|}{ Model 4b: Model 3+Physical activity (yes } \\
\hline vs. no) & 0.84 & $0.63-1.13$ & 0.80 & $0.54-1.21$ & 0.87 & $0.58-1.31$ \\
\hline \multicolumn{7}{|l|}{ Model 5: Model 4a+Reduced CHO diet vs. } \\
\hline Healthy High CHO diet & 0.69 & $0.32-1.50$ & 0.09 & $0.01-0.88^{*}$ & 1.10 & $0.42-2.83$ \\
\hline Model 6: Model 5+Siesta (yes vs. no) & 4.05 & $1.31-12.52$ & 2.80 & $0.31-24.80$ & 3.43 & $1.08-10.9^{*}$ \\
\hline
\end{tabular}

OR: Odds Ratio; CI: Confidence Interval; estimated by binary logistic regression; CHO: Carbohydrates

*Indicates a significant change $(p<0.05)$ in -2 loglikelihood from the previous (nested) model; 


\section{References}

1. Alberti KG, Eckel RH, Grundy SM, Zimmet PZ, Cleeman JI, Donato KA, et al. Harmonizing the metabolic syndrome: a joint interim statement of the International Diabetes Federation Task Force on Epidemiology and Prevention; National Heart, Lung, and Blood Institute; American Heart Association; World Heart Federation; International Atherosclerosis Society; and International Association for the Study of Obesity. Circulation. 2009;120(16):1640-5.

2. Kaur J. A comprehensive review on metabolic syndrome. Cardiology research and practice. 2014;2014:943162.

3. Grundy SM, Brewer HB, Jr., Cleeman JI, Smith SC, Jr., Lenfant C. Definition of metabolic syndrome: report of the National Heart, Lung, and Blood Institute/American Heart Association conference on scientific issues related to definition. Arteriosclerosis, thrombosis, and vascular biology. 2004;24(2):e13-8.

4. Grundy SM. Metabolic syndrome pandemic. Arteriosclerosis, thrombosis, and vascular biology. 2008;28(4):629-36.

5. Wu TT, Chen IJ, Cho SL, Chiou AF. The Relationship Between Health-Promoting Behaviors and Metabolic Syndrome in Community-Dwelling Older Adults. Biological research for nursing. 2016.

6. Borlaug BA, Reddy YN. Getting at the Heart of Central Obesity and the Metabolic Syndrome. Circulation Cardiovascular imaging. 2016;9(6).

7. D'Amore S, Vacca M, Cariello M, Graziano G, D'Orazio A, Salvia R, et al. Genes and miRNA expression signatures in peripheral blood mononuclear cells in healthy subjects and patients with metabolic syndrome after acute intake of extra virgin olive oil. Biochimica et biophysica acta. 2016.

8. Hazarika A, Kalita H, Chandra Boruah D, Chandra Kalita M, Devi R. Pathophysiology of metabolic syndrome: The onset of natural recovery on withdrawal of a high-carbohydrate, high-fat diet. Nutrition (Burbank, Los Angeles County, Calif). 2016.

9. Spahis S, Borys JM, Levy E. Metabolic Syndrome as a Multifaceted Risk Factor for Oxidative Stress. Antioxidants \& redox signaling. 2016.

10. Xiao J, Shen C, Chu MJ, Gao YX, Xu GF, Huang JP, et al. Physical Activity and Sedentary Behavior Associated with Components of Metabolic Syndrome among People in Rural China. PloS one. 2016;11(1):e0147062.

11. Kastorini CM, Panagiotakos DB, Chrysohoou C, Georgousopoulou E, Pitaraki E, Puddu PE, et al. Metabolic syndrome, adherence to the Mediterranean diet and 10-year cardiovascular disease incidence: The ATTICA study. Atherosclerosis. 2016;246:87-93.

12. Kim NH, Shin DH, Kim HT, Jeong SM, Kim SY, Son KY. Associations between Metabolic Syndrome and Inadequate Sleep Duration and Skipping Breakfast. Korean journal of family medicine. 2015;36(6):273-7.

13. Tardy M, Gonthier R, Barthelemy JC, Roche F, Crawford-Achour E. Subjective sleep and cognitive complaints in 65 year old subjects: a significant association. The PROOF cohort. The journal of nutrition, health \& aging. 2015;19(4):424-30. 

metabolic syndrome: an updated systematic review. Reviews in endocrine \& metabolic disorders. 2013;14(3):255-63. 15. Fougere B, Mazzuco S, Spagnolo P, Guyonnet S, Vellas B, Cesari M, et al. Association between the Mediterranean-style Dietary Pattern Score and Physical Performance: Results from TRELONG Study. The journal of nutrition, health \& aging. 2016;20(4):415-9.

429 16. Lin D, Sun K, Li F, Qi Y, Ren M, Huang C, et al. Association between habitual daytime napping and metabolic syndrome: a population-based study. Metabolism: clinical and experimental. 2014;63(12):1520-7.

17. Rochlani Y, Pothineni NV, Mehta JL. Metabolic Syndrome: Does it Differ Between Women and Men? Cardiovascular drugs and therapy / sponsored by the International Society of Cardiovascular Pharmacotherapy. 2015;29(4):329-38. 18. Executive Summary of The Third Report of The National Cholesterol Education Program (NCEP) Expert Panel on Detection, Evaluation, And Treatment of High Blood Cholesterol In Adults (Adult Treatment Panel III). Jama. 2001;285(19):2486-97. metabolic syndrome: report of the American Heart Association/National Heart, Lung, and Blood Institute/American Diabetes Association conference on scientific issues related to management. Arteriosclerosis, thrombosis, and vascular biology. 2004;24(2):e19-24. 20. Tyrovolas S, Pounis G, Bountziouka V, Polychronopoulos E, Panagiotakos DB. Repeatability and validation of a short, semi-quantitative food frequency questionnaire designed for older adults living in Mediterranean areas: the MEDIS-FFQ. Journal of nutrition for the elderly. 2010;29(3):311-24.

446 21. Panagiotakos DB, Pitsavos C, Stefanadis C. Dietary patterns: a Mediterranean diet score and its relation to clinical and biological markers of cardiovascular disease risk. Nutrition, metabolism, and cardiovascular diseases : NMCD. 2006;16(8):559-68. 22. Bursztyn M, Ginsberg G, Stessman J. The siesta and mortality in the elderly: effect of rest without sleep and daytime sleep duration. Sleep. 2002;25(2):187-91. 23. Papathanasiou G, Georgoudis G, Papandreou M, Spyropoulos P, Georgakopoulos D, Kalfakakou V, et al. Reliability measures of the short International Physical Activity Questionnaire (IPAQ) in Greek young adults. Hellenic journal of cardiology : HJC = Hellenike kardiologike epitheorese. 2009;50(4):283-94. Successful aging, dietary habits and health status of elderly individuals: a k-dimensional approach within the multi-national MEDIS study. Experimental gerontology. 2014;60:57-63. 25. Tyrovolas S, Zeimbekis A, Bountziouka V, Voutsa K, Pounis G, Papoutsou S, et al. Factors Associated with the Prevalence of Diabetes Mellitus Among Elderly Men and Women Living in Mediterranean Islands: The MEDIS Study. The review of diabetic studies : RDS. 2009;6(1):54-63.

462 26. Lewis F, Butler A, Gilbert L. A unified approach to model selection using the 463 likelihood ratio test. Methods in Ecology and Evolution. 2011;2(2):155-62. 
464 27. Yamada T, Hara K, Shojima N, Yamauchi T, Kadowaki T. Daytime Napping and the

465 Risk of Cardiovascular Disease and All-Cause Mortality: A Prospective Study and Dose466 Response Meta-Analysis. Sleep. 2015;38(12):1945-53.

467 28. Xu SH, Qiao N, Huang JJ, Sun CM, Cui Y, Tian SS, et al. Gender Differences in 468 Dietary Patterns and Their Association with the Prevalence of Metabolic Syndrome among 469 Chinese: A Cross-Sectional Study. Nutrients. 2016;8(4).

470 29. Olszanecka A, Kawecka-Jaszcz K, Czarnecka D. Association of free testosterone and 471 sex hormone binding globulin with metabolic syndrome and subclinical atherosclerosis but 472 not blood pressure in hypertensive perimenopausal women. Archives of medical science : 473 AMS. 2016;12(3):521-8.

474 30. Meng Z, Liu M, Zhang Q, Liu L, Song K, Tan J, et al. Gender and Age Impacts on the 475 Association Between Thyroid Function and Metabolic Syndrome in Chinese. Medicine. $476 \quad 2015 ; 94(50): \mathrm{e} 2193$.

477 31. Lee G, Choi HY, Yang SJ. [Effects of Dietary and Physical Activity Interventions on 478 Metabolic Syndrome: A Meta-analysis]. Journal of Korean Academy of Nursing. 479 2015;45(4):483-94.

480 32. Panagiotakos DB, Georgousopoulou EN, Pitsavos C, Chrysohoou C, Metaxa V, 481 Georgiopoulos GA, et al. Ten-year (2002-2012) cardiovascular disease incidence and all482 cause mortality, in urban Greek population: the ATTICA Study. International journal of 483 cardiology. 2015;180:178-84. 